\title{
Youtube Sebagai Sumber Belajar Generasi Milenial
}

\author{
Erik Fahron Setiadi, Alia Azmi, Junaidi Indrawadi \\ Program Studi Pendidikan Pancasila dan Kewarganegaraan \\ Universitas Negeri Padang \\ E-mail: erikfahronsetiadi@gmail.com
}

\section{ABSTRAK}

Penelitian ini bertujuan untuk mengetahui bagaimana pemanfaatan media YouTube sebagai salah satu sumber belajar mahasiswa pada matakuliah rumpun politik kewarganegaraan ditinjau dari aspek penggunaan, tindak lanjut yang dilakukan, manfaat yang diperoleh, serta kendala apa saja yang dialami oleh mahasiswa Jurusan Ilmu Sosial Politik dalam menggunakan media YouTube sebagai sumber belajar. Lokasi penelitian ini berada di lingkungan Fakultas Ilmu Sosial Universitas Negeri Padang dan lingkungan sekitar tempat tinggal mahasiswa. Penelitian dilakukan dengan metode Survey. Populasi penelitian adalah seluruh mahasiswa Jurusan Ilmu Sosial Politik tahun masuk 2016-2017. Teknik pengambilan sampel dalam penelitian ini dilakukan dengan "Proportional Random Sampling". Teknik pengumpulan data dilakukan melalui kuisioner, wawancara, dan dokumentasi. Data yang dikumpulkan tersebut dianalisis dengan analisis deskriptif dengan hitungan persentase. Kemudian setelah dilakukan analisis deskriptif dikonfirmasikan kembali kepada responden dengan wawancara. Hasil penelitian mengungkapkan bahwa jumlah mahasiswa yang menggunakan YouTube sebagai sumber belajar rumpun politik kewarganegaraan rendah yaitu 22,95\%. penelitian juga mengungkapkan bahwa tindak lanjut dari mahasiswa yang menggunakan YouTube sebagai sumber belajar rumpun politik dalam taraf cukup.

Kata Kunci: Teknologi Informasi, YouTube Website, Sumber Belajar

\section{ABSTRACT}

The aims of this study was to find out how the utilization of YouTube media as a source of learning in the course of citizenship politics in terms of usage aspects, follow-up actions, benefits and constraints that are felt by the students of socio-political department in using YouTube as learning source. The location of this study is in the Faculty of Social Science Padang State Universiy and the environment where the students live. The reaserch was conducted with the survey method. The population of the research was all of sociopolitical sciences students' academic year 2016-2017. The sampling techniques used in this research were Proportional Random Sampling. The technique of data collection was questionnaire, interviews and documentation. The data collected was analyzed by descriptive analysis with a percentage count. Then after descriptive analysis a confimed again to the respondents with the interview. the results of the study revealed that the number of students using YouTube as a learning resource for political citizenshipis rated is considered low was 
22,95\% . the results also revealed that the follow-up of students who used YouTube as a source of learning for citizenship political groups was in enough level.

Keywords : Information Technology, YouTube Website, Learning Source

\begin{tabular}{cl}
\hline Received: $2019-04-29$ & Accepted: 2019-09-02 \\
\hline \hline
\end{tabular}

\section{PENDAHULUAN}

Perkembangan teknologi informasi di zaman globalisasi saat ini sangatlah cepat. Masyarakat sudah terbiasa menggunakan teknologi informasi dalam kehidupan seharihari. Teknologi Informasi adalah suatu teknologi yang digunakan untuk mengolah data (Uno, Lamatenggo, \& Koni, 2011). Pengolahan itu termasuk menyimpan, menyusun, mendapatkan, memproses, memanipulasi data dalam berbagai cara untuk menghasilkan informasi yang berkualitas, yaitu informasi yang akurat, tepat waktu, dan relevan. Salah satu inovasi teknologi informasi yang sedang trend adalah YouTube. YouTube telah menjadi situs berbagi video terbesar dan terpopuler di dunia saat ini. Situs ini memfasilitasi penggunanya untuk mengunggah video maupun menyiarkan video secara langsung yang dapat ditonton oleh pengguna lain diseluruh dunia secara gratis.

Berdasarkan survey yang dilakukan YouTube, YouTube telah memiliki lebih dari 1 miliar pengguna, yang berarti hampir sepertiga dari seluruh pengguna internet. Mayoitas pengguna berusia 18-34 tahun dan lebih dari $70 \%$ waktu menonton video di YouTube berasal dari perangkat seluler. 1 miliar jam konten ditonton setiap harinya. Google mewakili YouTube menyampaikan hasil riset yang dilaksanakan bersama Kantar
TNS tentang pengguna di Indonesia. PT. Kantar TNS Indonesia adalah sebuah perusahaan yang bergerak dibidang riset pasar dan informasi pasar. Berdasarkan hasil riset, penonton di Indonesia rata-rata menghabiskan waktu 59 menit setiap harinya di YouTube. Menurut hasil riset 92\% pengguna internet indonesia menyatakan YouTube adalah tujuan pertama mereka ketika mencari video. Dari segi kuantitas penonton, YouTube sudah menyaingi televisi sebagai sarana media yang paling sering diakses orang indonesia. Dari 1.500 responden yang terlibat dalam penelitian, $53 \%$ menyatakan mengakses YouTube setiap hari, dan $57 \%$ menyatakan menonton televisi setiap hari.

Tersedianya sumber informasi yang baik dalam pembelajaran akan dapat mengatasi hambatan ruang dan waktu dalam proses pembelajaran dikelas (Moeis, Indrawadi, Anggraini, \& Fatmariza, 2018). Sumber belajar merupakan suatu sistem yang terdiri dari sekumpulan bahan atau situasi yang diciptakan dengan sengaja dan dibuat agar memungkinkan peserta didik belajar secara individual (Warsita, 2008). Dengan adanya sumber belajar yang memadai bukan hanya akan mempermudah pemahaman materi pelajaran oleh mahasiswa, tetapi juga akan melengkapi, memelihara, dan memperkaya ilmu dari seorang mahasiswa. Penguasaan teknologi 
informasi sudah menajadi gaya hidup bagi sebagaian besar masyarakat terutama pemuda (Irwan, Luthfi, \& Waldi, 2019). YouTube bisa menjadi sumber belajar bagi Mahasiswa yang kreatif. Adanya YouTube akan memberikan paradigma baru dalam mencari sumber belajar khususnya sumber belajar di bidang politik dan pemerintahan yang tujuan dari bidang tersebut ialah agar dapat membentuk sikap dan opini mengenai berbagai hal, terutama hal yang berkaitan dengan politik.

Banyak konten yang berisi informasi politik dan pemerintahan di YouTube akan tetapi mahasiswa memiliki kecenderungan menggunakan internet untuk membuka situs selain YouTube untuk aktifitas pembelajaran dan membuat tugas. padahal pada YouTube banyak sekali hal positif yang dapat dijadikan mahasiswa sebagai sumber informasi khususnya pada tayangan tentang politik di Indonesia. Kelebihan YouTube sebagai media pembelajaran yaitu: 1) Informatif, maksudnya adalah YouTube dapat memberikan informasi termasuk berbagai perkembangan ilmu dan tekhnologi yang terjadi saat ini. 2) Cost effective, maksudnya adalah YouTube dapat diakses secara gratis melalui jaringan internet. 3) Potensial, artinya situs ini sangat populer dan semakin banyak video yang ada pada YouTube sehingga bisa memberikan pengaruh terhadap pendidikan. 4) Praktis dan lengkap, maksudnya adalah YouTube bisa digunakan dengan mudah oleh semua kalangan dan banyak video yang bisa dijadikan sebagai sumber informasi. 5) Shareable, artinya video yang ada di YouTube dapat dibagikan ke situs lainya dengan cara membagikan link yang ada pada video tersebut. 6) Interaktif, maksudnya adalah YouTube dapat memfasilitasi untuk tanya jawab dan diskusi melalui kolom komentar (Suryaman, 2015).

Selain kecendrungan mahasiswa menggunakan internet dalam membantu aktifitas pembelajaran dan membuat tugas, masalah terkadang dari dosen yang melarang mahasiswa menggunakan gadget dan laptop dalam proses pembelajaran sehingga sumber belajar mahasiswa dalam proses pembelajaran hanya bersifat kontekstual. Kemudian terdapat beberapa pula beberapa tantangan terkait penggunaan YouTube dalam pembelajaran yang diungkapkan oleh Suryaman (2015), yaitu: 1) Ketersediaan video, pada situs YouTube ada beberapa video yang hanya tersedia dalam rentang waktu tertentu, sehingga mahasiswa atau pendidik harus memperhatikan ketersediaan video tersebut (Burke \& Snyder, 2008). 2) Kualitas Konten, agar video tidak ketinggalan zaman, pengguna YouTube khususnya mahasiswa dan Pendidik harus memperhatikan tanggal video. Kemudian perlu diperhatikan kualitas isi daari video tersebut, karena sering kali video dibuat perorangan tanpa batas. Seringkali video juga melanggar aturan kesusilaan karena menampilkan video yang tidak pantas atau tidak senonoh (Buckley, Adelson, \& Agazio, 2009). 3) Proses pencarian, tantangan berikutnya adalah dalam proses pencarian video. Suatu pencarian video dapat menghasilkan tampilan video yang sangat banyak sehingga membuat pengguna bingung dalam memilih video agar mendapatkan informasi yang sesuai. Adapun salah satu cara untuk 
memperkecil pencarian adalah dengan fokus pada username yang mengunggah video (Sharoff, 2011). Selain itu, pengguna YouTube bisa menandai (mendiskriptor/tag) pengguna lainnya berdasarkan tema pembelajaran sehingga mempermudah mereka mencari video sesuai topik yang diharapkan.

Berdasarkan hasil observasi peneliti kepada mahasiswa Jurusan Ilmu Sosial Politik di UNP, pada tanggal 16 juli 2018, diketahui bahwa sebagian besar mahasiswa cenderungan menggunakan internet dalam aktifitas dilingkungan kampus. Kemudian hasil wawancara yang peneliti lakukan dengan sepuluh orang mahasiswa Jurusan Ilmu Sosial Politik diketahui bahwa, hanya dua orang saja yang memang benar menjadikan YouTube sebagai sumber belajar bidang politik dan pemerintahan. Pemanfaatan yang dimaksud adalah menggunakan media YouTube dimulai dengan proses pencarian, menonton video tentang informasi politik dan pemerintahan di YouTube, menganalisis dan membahas informasi tersebut, kemudian dari hasil analisis informasi tersebut disampaikan dalam diskusi ataupun dijadikan sebagai bagian dari muatan tugas yang diberikan oleh dosen.

Dari permasalahan tersebut penelitian ingin melihat bagaimana Mahasiswa Jurusan Ilmu Sosial Politik FIS UNP memanfaatkan YouTube sebagai sumber belajar rumpun politik kewarganegaraan. Teori yang digunakan dan dianggap relevan dalam penelitian ini adalah teori attitudes and behavior yang dikemukakan oleh Triandis (1980) yang mengungkapkan faktor-faktor berpengaruh dalam pemanfaatan teknologi informasi adalah sebagai berikut: 1) faktor sosial, faktor sosial merupakan internalisasi kultur subjektif kelompok dan persetujuan interpersonal tertentu yang dibuat individual dengan yang lain dalam situasi sosial tertentu; 2) affect (perasaan), Affect dapat diartikan bagaimana perasaan individu atas pekerjaan, apakah menyenangkan atau tidak menyenangkan, rasa suka atau tidak suka dalam melakukan pekerjaan individual dengan menggunakan teknologi informasi; 3) kompleksitas, Kompleksitas didefinisikan sebagai tingkat inovasi yang dipersepsikan sesuatu yang relatif sulit untuk dimengerti dan digunakan, jika sulit digunakan akan semakin rendah penerimaan; 4) kesesuaian tugas, Kesesuaian tugas dan teknologi dipengaruhi oleh interaksi antara karakteristik individu pemakai, teknologi yang digunakan, dan tugas yang berbasis teknologi; 5) konsekuensi jangka panjang, Konsekuensi jangka panjang diukur dari output yang dihasilkan apakah mempunyai keuntungan pada masa yang akan datang, seperti peningkatan fleksibilitas dalam perubahan pekerjaan atau peningkatan kesempatan untuk pekerjaan yang lebih baik. 6) dan fasilitas, dalam konteks pemanfaatan teknologi informasi, kondisi yang mefasilitasi dapat dimasukkan sebagai faktor yang mempengaruhi pemanfaatan teknologi informasi (Jin, 2003).

Selain itu adapula teori Technology Acceptance Model (TAM) atau Model Penerimaan Teknologi yang merupakan salah satu teori tentang penggunaan system teknologi informasi yang dianggap sangat berpengaruh dan umumnya 
digunakan untuk menjelaskan penerimaan individual terhadap penggunaan sistem teknologi informasi (Jogiyanto, 2007). Penerimaan pengguna dalam menggunakan sistem teknologi informasi dapat didefinisikan sebagai keinginan yang nampak didalam kelompok pengguna untuk menerapkan sistem teknologi informasi tersebut dalam pekerjaannya (Hendrawati, 2013). Semakin menerima sistem teknologi informasi yang baru semakin cepat adaptasi pada sistem teknologi informasi yang baru tersebut, akan tetapi apabila pemakai tidak mau menerima sistem teknologi informasi yang baru, maka perubahan sistem tersebut tidak memberikan keuntungan yang banyak bagi organisasi atau pengguna. Dari dua teori tersebut peneliti ingin mengetahui seberapa jauh dan bagaimana tindak lanjut mahasiswa Jurusan Ilmu Sosial Politik FIS UNP dalam memanfaatkan YouTube sebgai sumber belajar rumpun politik kewarganegaraan, kemudian bagaimana manfaat dan kendala yang rasakan mahasiswa Jurusan Ilmu Sosial Politik FIS UNP dalam menggunakan YouTube sebagai sumber belajar.

\section{METODE PENELITIAN}

Jenis penelitian yang digunakan adalah penelitian survey dengan pendekatan deskriptif yang bertujuan untuk menggambarkan dan menafsirkan data sebagaimana adanya. Populasi dalam penelitian ini adalah mahasiswa Jurusan Ilmu Sosial Politik tahun masuk 2016 dan 2017 di Universitas Negeri Padang dengan jumlah mahasiswa yaitu 283 orang. Penelitian dilaksanakan pada bulan
Juni sampai dengan Juli tahun 2018. Adapun pengambilan sampel dalam penelitian ini menggunakan teknik Proportional Random Sampling dengan jumlah sampel yaitu 74 orang. Data dikumpulkan dengan menggunakan angket dan dilengkapi dengan wawancara agar hasil yang didapatkan kebih baik. Data yang diperoleh dari wawancara dianalisis dengan cara yaitu reduksi data, penyajian data, dan membuat kesimpulan. Data yang diperoleh dari angket dianalisis dengan menggunakan rumus persentase.

\section{HASIL DAN PEMBAHASAN}

\section{Penggunaan YouTube}

Grafik 1. Penggunaan YouTube oleh mahasiswa oleh mahasiswa Jurusan Ilmu Sosial politik FIS UNP tahun masuk 2016 dan 2017

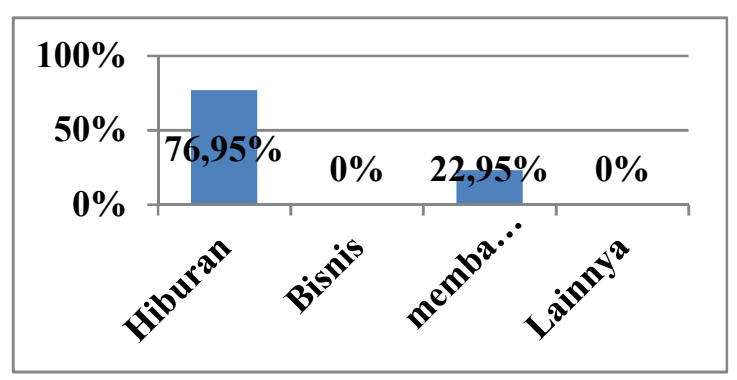

Penelitian ini menunjukkan bahwa semua mahasiswa Jurusan Ilmu Sosial Politik UNP tahun masuk 2016 dan 2017 telah mengenal dan menggunakan YouTube dalam kehidupan sehari-hari. Tetapi penggunaan YouTube tersebut lebih banyak untuk mengakses konten hiburan dibandingkan untuk membantu perkuliahan. Hal ini diketahui dari hasil penelitian pada grafik 1 yang menunjukkan bahwa tingkat penggunaan YouTube untuk membantu perkuliahan dengan jumlah persentase $22,95 \%$ atau 17 
orang. Dari hasil penelitian ini juga diketahui bahwa frekuensi waktu mahasiswa yang mengunakan YouTube sebagai sumber belajar adalah kurang dari satu jam dengan Smartphone atau Laptop pribadi dan memanfaatkan fasilitas Wi-Fi kampus maupun area yang mempunyai akses Wi-Fi lainnya. Mahasiswa mengakses konten video dialog isu kenegaraan seperti yang ada pada channel Najwa Shihab yaitu Mata Najwa dan Narasi $\mathrm{Tv}$, serta video dialog isu politik yang ada pada channel TV One yaitu Indonesian Lawyers Club. Karena dua channel YouTube tersebut lah yang sering membahas isu politik kewarganegaraan yang sedang terjadi.

Menurut Triandis (1980) faktorfaktor yang mempengaruhi penerapan teknologi informasi adalah faktor sosial, Affect (perasaan), Kompleksitas, Kesesuaian Tugas, Konsekuensi jangka panjang, dan kondisi Fasilitas (Jin, 2003). Dari hasil penelitian diketahui bahwa faktor-faktor penerapan teknologi informasi sangan berkaitan dengan penggunaan YouTube sebagai sumber belajar, yaitu:

\section{a. Faktor sosial}

Pada era saat ini penggunaan internet oleh masyarakat sangat tinggi Sehingga menjadi hal yang lumrah ketika mahasiswa menggunakan YouTube. Berdasarkan wawancara diperoleh pernyataan bahwa faktor sosial yang mempengaruhi penggunanan YouTube sebagai sumber belajar bidang politik kewarganegaraan oleh mahasiswa adalah teman-teman dilingkungan tempat tinggal dan dilingkungan kampus. Banyak mahasiswa yang menggunakan YouTube hanya sebagai media hiburan dan menggunakan sosial media lain untuk menyelsaikan tugas, ketertarikan mahasiswa untuk menonton atau mencari video tentang politik kewarganegaraan meningkat jika isu politik kewarganegaaraan tersebut sedang banyak di perbincangkan.

\section{b. Kompleksitas}

Berdasarkan faktor kompleksitas, mahasiswa Jurusan Ilmu Sosial Politik UNP tidak mengalami kesulitan dalam menggunakan YouTube karena tampilan YouTube hampir sama dengan tampilan pada sosial media lainnya yang mereka gunakan. Berdasarkan wawancara diperoleh hasil bahwa mahasiswa lebih sering menonton video politik dan pemerintahan yang ada pada menu trending di YouTube, Akan tetapi mahasiswa mengalami kesulitan dalam mencari video politik dan pemerintahan yang mreka inginkan, hal ini dikarenakan banyak muncul video yang tidak berhubungan dengan informasi yang mereka cari. Berdasarkan wawancara diperoleh hasil bahwa mahasiswa lebih sering menonton video politik dan pemerintahan yang ada pada trending YouTube.

\section{c. Affect (perasaan)}

Berdasarkan faktor affect (perasaan), dari jawaban angket yang dijawab oleh mahasiswa yang menggunakan YouTube sebagai sumber belajar politik kewarganegaraan ini menunjukkan bahwa mahasiswa yang menggunakan YouTube sebagai sumber belajar karena dengan menggunakan YouTube lebih mudah memahami materi perkuliahan, YouTube menumbuhkan rasa ingin tahu saya terhadap isu politik dan pemerintahan, YouTube mempunyai informasi yang lebih rinci dari pada buku dan dosen, YouTube mempunyai informasi yang update 
dari pada media lainnya, YouTube sebagai media pelengkap informasi tentang materi perkuliahan selain dari dosen.

\section{d. Kesesuaian Tugas}

Berdasarkan faktor kesesuaian tugas, mahasiswa Jurusan Ilmu Sosial politik UNP tahun masuk 2016 dan 2017 yang menggunakan YouTube sebagai sumber belajarnya mengungkapkan bahwa terjadi peningkatan pengetahuan dan informasi mereka terhadap politik. Dari hasil penelitian melalui angket diketahui bahwa mahasiswa menonton video dialog isu politik pemerintahan pada YouTube. Hal ini sesaui dengan hasil wawancara bahwa konten-konten yang sering ditemui sebagai sumber informasi politik kewarganegaraan adalah pada video oleh Najwa Sihab pada channel Narasi TV dan channel acara Mata Najwa, kemudian pada channel Indonesia Lawyers Club (ILC).

\section{e. Konsekuensi Jangka Panjang}

Berdasarkan konsekuensi jangka panjang, tak dapat dipungkiri bahwa teknologi informasi masih terus berInovasi. Hal ini bisa saja menjadikan mahasiswa tertinggal apabila tidak menguasai teknologi informasi sebagai sumber belajar. Oeh karena itu dimasa sekarang mahasiswa harus peka terhadap informasi yang tersaji di media YouTube karena banyak menyajikan video ter-uptade tentang isu yang terjadi.

\section{f. Kondisi Fasilitas}

Berdasarkan fasilitas, mahasiswa Jurusan Sosial Politik UNP lebih banyak menggunakan Smartphone untuk mengakses YouTube sebagai sumber belajar karena lebih praktis jika dibandingkan dengan menggunakan Laptop. Dari hasil penelitian diketahui bahwa mahasiswa Jurusan Ilmu Sosial Politik UNP lebih dominan mengakses YouTube dengan menggunakan perangkat Smartphone dengan menggunakan fasilitas wifi yang ada pada lingkungan nya, baik dikampus maupun dilingkungan tempat tinggal, hal ini dikarenakan biaya untuk pembelian kuota internet yang cukup membebani mahasiswa.

Tindak Lanjut Pemanfaatan YouTube sebagai Sumber Belajar Rumpun Politik kewarganegaraan

Grafik 2 Tindak lanjut dalam mengakses YouTube sebagai sumber belajar politik kewarganegaaran oleh mahasiswa Jurusan Ilmu Sosial politik FIS UNP tahun masuk 2016 dan 2017

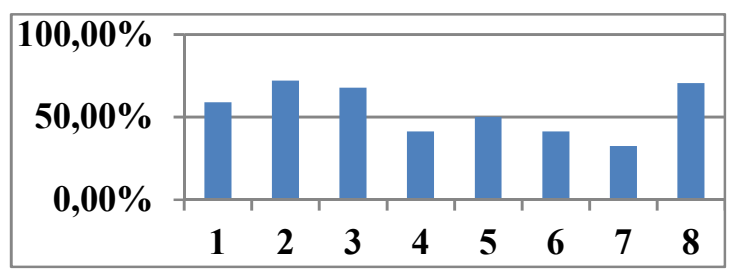

Grafik 2 menunjukkan hasil interpretasi dari angket tindak lanjut dalam mengakses YouTube sebagai sumber belajar politik kewarganegaaran oleh mahasiswa Jurusan Ilmu Sosial politik FIS UNP tahun masuk 2016 dan 2017 sebagai sumber belajar, dari 8 pertanyaan yang dijawab oleh 17 responden dengan urutan pertanyaan angket sebagai berikut: 1) Berinisiatif sendiri Mencari video politik dan kewarganegaraan di YouTube sebagai sumber belajar politik dan kewarganegaran. 2) Menonton video politik dan kewarganegaraan di YouTube yang dibagikan ke media sosial. 3) Menganalisis video politik dan kewarganegaraan di YouTube sebagai sumber informasi pembelajaran. 4) Menyampaikan hasil analisis video politik dan 
kewarganegaraan di YouTube dalam diskusi kelas. 5) Berdiskusi dengan teman tentang video politik dan kewarganegaraan di YouTube yang telah ditonton. 6) Membagikan video politik dan kewarganegaraan yang telah ditonton di YouTube ke media sosial. 7) Berkomentar di media sosial tentang tanggapan terhadap video politik kewarganegaraan yang telah ditonton. 8) Saya menggunakan YouTube sebagai sumber beajar politik dan pemerintahan karena disuruh dosen.

Hasil interpretasi rata-rata pada pertanyaan angket tentang tindak lanjut dalam mengakses YouTube sebagai sumber belajar politik kewarganegaaran oleh mahasiswa Jurusan Ilmu Sosial politik FIS UNP tahun masuk 2016 dan 2017 sebagai sumber belajar yaitu $54,22 \%$ atau berada pada skala cukup. Dari hasil penelitian diketahui bahwa mahasiswa Jurusan Ilmu Sosial Politik kurang mempunyai inisiatif mencari video politik kewarganegaraan di YouTube. Perlu adanya motivasi berupa tugas dari dosen agar mahasiswa lebih aktif dalam mencari sumber belajar berupa video di YouTube.

Kemudian berdasarkan hasil wawancara diketahui bahwa Mahasiswa Jurusan Ilmu Sosial politik mengakses YouTube sebagai sumber belajar politik kewarganegaraan dengan cara mencari video yang berkaitan dengan materi politik ataupun, menonton video tentang isu politik pemerintahan yang sedang trending, menganalisis video dan komentar yang bisa dijadikan informasi politik, berdiskusi dan sharing tentang video politik pemerintahan yang didapatkan kepada teman-teman.

Manfaat dan Kendala Penggunaan YouTube sebagai Sumber Belajar Rumpun Politik kewarganegaraan

Grafik 3 Alasan menggunakan YouTube sebagai sumber belajar politik kewarganegaaran oleh mahasiswa Jurusan Ilmu Sosial politik FIS UNP tahun masuk 2016 dan 2017

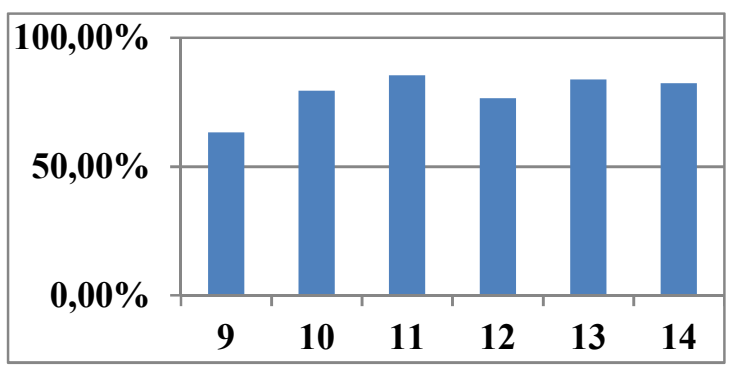

Grafik 3 menunjukkan hasil interpretasi angket alasan menggunakan YouTube sebagai sumber belajar politik kewarganegaaran oleh mahasiswa Jurusan Ilmu Sosial politik FIS UNP tahun masuk 2016 dan 2017 sebagai sumber belajar, dari 6 pertanyaan yang dijawab oleh 17 responden dengan urutan pertanyaan sebagai berikut: 9) Saya lebih mudah memahami materi perkuliahan dibidang politik dan pemerintahan lewat YouTube. 10) Dengan menggunakan YouTube menumbuhkan rasa ingin tahu saya terhadap isu politik dan pemerintahan. 11) Saya menggunakan YouTube karena YouTube mempunyai informasi yang lebih rinci dari pada buku dan dosen. 12) Saya menggunakan YouTube karena YouTube mempunyai informasi yang update dari pada media lainnya. 13) Saya menggunakan YouTube sebagai media pelengkap informasi tentang materi perkuliahan selain dari dosen. 14) Saya lebih suka mencari informasi tentang politik dan 
pemerintahan di YouTube dari pada di pustaka.

Hasil interpretasi rata-rata pada pertanyaan angket tentang alasan dalam menggunakan YouTube sebagai sumber belajar politik kewarganegaaran oleh mahasiswa Jurusan Ilmu Sosial politik FIS UNP tahun masuk 2016 dan 2017 sebagai sumber belajar yaitu $78,42 \%$ atau berada pada skala baik. Mahasiswa Jurusan Ilmu Sosial politik meyakini bahwa YouTube adalah salah satu sumber belajar yang bisa digunakan untuk memperoleh informasi politik kewarganegaraan karena pada hasil penelitian menunjukan bahwa mahasiswa merasakan kemudahan, kelengkapan informasi, dan cepat dalam mendapatkan informasi.

Terlepas dari alasan mahasiswa menggunakan teknologi YouTube sebagai sumber belajar. Terdapat manfaat yang baik dalam penggunaan YouTube sebagai sumber belajar politik kewarganegaraan, manfaat tersebut diketahui dari hasil wawancara kepada mahasiswa Jurusan Ilmu Sosial Politik UNP yaitu mahasiswa Jurusan Ilmu Sosial politik merasakan kemudahan dalam mencari informasi tentang politik kewarganegaraan di YouTube, karena pada sistim tampilan menu trending di YouTube yang cukup memberikan alternatif konten yang dicari. Kemudian manfaat yang dirasakan selanjutnya adalah informasi tentang perkembangan isu politik yang didapatkan bisa lebih rinci dari apa yang ada di sumber belajar lainnya.

$$
\text { Menurut Suryaman }
$$
terdapat beberapa tantangan terkait penggunaan YouTube dalam pembelajaran, yaitu Ketersediaan video, Kualitas Konten, Proses pencarian (Suryaman, 2015). Dari hasil wawancara kepada mahasiswa Jurusan Ilmu Sosial Politik UNP dapat terlihat bahwa Mahasiswa Jurusan Ilmu Sosial politik merasakan kendala dalam mengakses YouTube sebagai sumber belajar yaitu sulitnya menemukan konten yang berkualitas kualitas dan sesuai dengan materi yang ada pada perkuliahan politik kewarganegaraan. Kemudian koneksi internet yang tidak stabil jika menggunakan fasilitas wifi kampus pada jam istirahat dan sulitnya mencari video politik pemerintahan yang berkualitas karena banyaknya rekomendasi video yang tidak berhubungan dengan tentang politik pemerintahan yang dicari. Adapun kendala yang dirasakan jika berada pada lingkungan kampus adalah ketika daya baterai perangkat yang mereka gunakan untuk mengakses YouTube sebagai sumber belajar politik pemerintahan akan habis, dan harus menunggu giiliran menggunakan stopkontak untuk mengisi ulang batrai perangkat yang dipakai. Hal tersebut menjelaskan bahwa YouTube memang dapat diakses secara gratis sesuai dengan pernyataan Suryaman, tetapi dalam penggunaannya mahasiswa harus mempunyai koneksi internet yang stabil dan mempunyai perangkat yang bisa menunjang agar lebih nyaman dalam menggunakan YouTube sebagai sumber belajar.

\section{KESIMPULAN}

Semua mahasiswa Jurusan Ilmu Sosial Politik FIS UNP Tahun Masuk 2016 dan 2017 telah mengenal dan menggunakan YouTube. namun pemanfaatan YouTube sebagai sumber belajar politik kewarganegaraan masih rendah yaitu 22,95\%. Dengan 
frekuensi waktu mahasiswa yang mengunakan YouTube sebagai sumber belajar adalah kurang dari satu jam dengan menggunakan Smartphone atau Laptop pribadi dan memanfaatkan fasilitas Wi-Fi kampus maupun area yang mempunyai akses Wi-Fi lainnya. Mahasiswa mengakses konten video dialog isu kenegaraan seperti yang ada pada channel Najwa Shihab yaitu Mata Najwa dan Narasi Tv, serta video dialog isu politik yang ada pada channel TV One yaitu Indonesian Lawyers Club. Adapun faktor-faktor yang mempengaruhi penerapan teknologi informasi, yaitu faktor sosial, Affect (perasaan), Kompleksitas, Kesesuaian Tugas, Konsekuensi jangka panjang, dan kondisi Fasilitas. Dari hasil penelitian diketahui bahwa faktor-faktor penerapan teknologi informasi sangat berkaitan dengan penggunaan YouTube sebagai sumber belajar. Manfaat yang dirasakan yaitu kemudahan dalam mencari informasi dan tentang politik kewarganegaraan di YouTube dan informasi tentang perkembangan isu politik yang didapatkan bisa lebih rinci dari apa yang ada di sumber belajar lainnya. Adapun kendala dalam penggunaan YouTube sebagai sumber belajar yaitu sulitnya menemukan konten yang berkualitas kualitas, koneksi internet yang tidak stabil, banyaknya rekomendasi video yang tidak berhubungan dengan tentang politik pemerintahan yang dicari, dan perangkat dan fasilitas yang terbatas.

Berdasarkan hasil penelitian yang diperoleh, peneliti menyarankan kepada mahasiswa untuk meningkatkan wawasan tentang pengetahuan teknologi informasi agar pemanfaatan media YouTube sebagai sumber belajar dapat lebih optimal sehingga dapat mencapai hasil yang maksimal dalam studinya. Kemudian peneliti menyarankan agar dosen mata kuliah memberikan arahan tentang suatu topik kepada mahasiswa. Hal ini dapat membiasakan mahasiswa untuk terus menggali ilmu pengetahuan tentang politik dan pemerintahan melalui media YouTube. peneliti juga menyarankan agar Universitas Negeri Padang meningkatkan sarana dan prasarana berupa koneksi internet yang cepat dan stabil dilingkungan Universitas Negeri Padang guna menunjang penggunaan media YouTube oleh mahasiswa untuk menonton video tentang politik dan pemerintahan. Terakhir peneliti mengahrapkan kepada peneliti selanjutnya agar dapat melakukan penelitian tentang pengaruh media YouTube terhadap proses dan hasil belajar mahasiswa.

\section{DAFTAR PUSTAKA}

Buckley, K. M., Adelson, L. K., \& Agazio, J. G. (2009). Reducing the risks of wound consultation: adding digital images to verbal reports. Journal of Wound Ostomy $\mathcal{E}$ Continence Nursing, 36(2), 163-170.

Burke, S. C., \& Snyder, S. L. (2008). YouTube: An Innovative Learning Resource for College Health Education Courses. International Electronic Journal of Health Education, 11, 39-46.

Hendrawati, T. (2013). Analisis Penerimaan Sistem Informasi Integrated Library System (INLIS): Studi Kasus di Perpustakaan Nasional RI. Jakarta: Visi Pustaka, 15(3), 2013.

Irwan, I., Luthfi, Z. F., \& Waldi, A. (2019). Efektifitas Penggunaan Kahoot! untuk Meningkatkan 
Hasil Belajar Siswa [Effectiveness of Using Kahoot! to Improve Student Learning Outcomes]. PEDAGOGIA: Jurnal Pendidikan, 8(1), 95-104.

Jin, T. F. (2003). Analisis faktor-faktor yang mempengaruhi pemanfaatan teknologi informasi dan pengaruh pemanfaatan teknologi informasi terhadap kinerja akuntan publik. Jurnal Bisnis Dan Akuntansi, 5(1), 1-26.

Jogiyanto, H. M. (2007). Sistem informasi keperilakuan. Yogyakarta: Andi Offset.

Moeis, I., Indrawadi, J., Anggraini, R., \& Fatmariza, F. (2018). Generating Value within Learning Activity: Integrating Storytelling with Reflective Practice in Civics and Character Education Class at College of Education. In Annual Civic Education Conference (ACEC 2018).

Sharoff, L. (2011). Integrating YouTube into the nursing curriculum. OJIN: The Online Journal of Issues in Nursing, 16(3).

Suryaman, M. (2015). Penggunaan Youtube sebagai Media Pengajaran Bahasa dan Sastra Indonesia pada Kurikulum 2013. Tersedia Di Https://Sites. Google. Com.

Triandis, H. C. (1980). Reflections on trends in cross-cultural research. Journal of Cross-Cultural Psychology, 11(1), 35-58.

Uno, H. B., Lamatenggo, N., \& Koni, S. M. A. (2011). Menjadi Peneliti PTK yang Profesional. Jakarta: Bumi Aksara.

Warsita, B. (2008). Teknologi pembelajaran landasan dan aplikasinya. Jakarta: Rineka Cipta, 135. 